ARTICLE

Received 21 Aug 2015 | Accepted 8 Jan 2016 | Published 19 Feb $2016 \quad$ DOl: 10.1038/ncomms10670 OPEN

\title{
Dissolution and ionization of sodium superoxide in sodium-oxygen batteries
}

Jinsoo Kim ${ }^{1, \star}$, Hyeokjun Park ${ }^{1, \star}$, Byungju Lee ${ }^{1,2}$, Won Mo Seong ${ }^{1}$, Hee-Dae Lim¹, Youngjoon Bae ${ }^{1}$ Haegyeom Kim¹,2, Won Keun $\mathrm{Kim}^{3}$, Kyoung Han $\mathrm{Ryu}^{3}$ \& Kisuk Kang ${ }^{1,2}$

With the demand for high-energy-storage devices, the rechargeable metal-oxygen battery has attracted attention recently. Sodium-oxygen batteries have been regarded as the most promising candidates because of their lower-charge overpotential compared with that of lithium-oxygen system. However, conflicting observations with different discharge products have inhibited the understanding of precise reactions in the battery. Here we demonstrate that the competition between the electrochemical and chemical reactions in sodium-oxygen batteries leads to the dissolution and ionization of sodium superoxide, liberating superoxide anion and triggering the formation of sodium peroxide dihydrate $\left(\mathrm{Na}_{2} \mathrm{O}_{2} \cdot 2 \mathrm{H}_{2} \mathrm{O}\right)$. On the formation of $\mathrm{Na}_{2} \mathrm{O}_{2} \cdot 2 \mathrm{H}_{2} \mathrm{O}$, the charge overpotential of sodium-oxygen cells significantly increases. This verification addresses the origin of conflicting discharge products and overpotentials observed in sodium-oxygen systems. Our proposed model provides guidelines to help direct the reactions in sodium-oxygen batteries to achieve high efficiency and rechargeability.

\footnotetext{
${ }^{1}$ Department of Materials Science and Engineering, Research Institute of Advanced Materials, Seoul National University, 1 Gwanak-ro, Gwanak-gu, Seoul 151-742, Republic of Korea. ${ }^{2}$ Center for Nanoparticle Research at Institute for Basic Science, Seoul National University, 1 Gwanak-ro, Gwanak-gu, Seoul 151-742, Republic of Korea. ${ }^{3}$ Environment and Energy Research Team, Division of Automotive Research and Development, Hyundai Motor Company, 37 Cheoldobangmulgwan-ro, Uiwang, Gyeonggi-do 437-815, Republic of Korea. * These authors contributed equally to this work. Correspondence and requests for materials should be addressed to K.K. (email: matlgen1@snu.ac.kr).
} 
T $o$ address the increasing use of renewable energy and launch of electric vehicles, the need for rechargeable batteries with high-energy densities has been growing more rapidly than ever before ${ }^{1,2}$. Among the available battery chemistries, metal-oxygen systems offer the highest energy density with the largest theoretical capacities. Unlike conventional lithium-ion batteries, the direct reaction between oxygen and light metals such as lithium and sodium in metaloxygen systems circumvents the need for a heavy transition metal redox couple in their operation, thereby making a high gravimetric energy density achievable ${ }^{3-7}$. The most intensively studied metal-oxygen system to date is the lithium-oxygen $\left(\mathrm{Li}-\mathrm{O}_{2}\right)$ battery, which shares a similar lithium chemistry with lithium-ion batteries. However, this system suffers from poor cycle stability and efficiency, which has retarded the feasibility of its use in practical systems ${ }^{8,9}$. In particular, the large charge overpotential over $1 \mathrm{~V}$, the main reason for the low efficiency, also accelerates the degradation of the electrode and electrolyte ${ }^{9}$. As an alternative, $\mathrm{Na}$ has been introduced to replace $\mathrm{Li}$ in $\mathrm{Li}-\mathrm{O}_{2}$ batteries with a few important merits ${ }^{10}$. Despite the reduction in the energy density resulting from the lower redox potential of $\mathrm{Na} / \mathrm{Na}^{+}, \mathrm{Na}$ resources are readily available, are less expensive than $\mathrm{Li}$ and can easily replace $\mathrm{Li}$ in the battery chemistry. It has been reported that the redox reactions in the sodium-oxygen $\left(\mathrm{Na}-\mathrm{O}_{2}\right)$ battery result in an extremely low charge overpotential $(\sim 0.2 \mathrm{~V})$ despite involving the formation of micrometre-sized sodium superoxide $\left(\mathrm{NaO}_{2}\right)$ cubic crystallites ${ }^{11-14}$. This unique phenomenon supports the idea that this system is a promising alternative not only in terms of the cost of materials but also regarding the potential practical performance advantages.

Notably, however, the reactions of $\mathrm{Na}-\mathrm{O}_{2}$ cells appear to be more diverse than those of $\mathrm{Li}-\mathrm{O}_{2}$ cells. Contrary to the initial report of $\mathrm{NaO}_{2}$ discharge products, some recent lines of work could not reproduce either the formation of the discharge product $\mathrm{NaO}_{2}$ or the low charge overpotential ${ }^{15-17}$. It was reported that sodium peroxide $\left(\mathrm{Na}_{2} \mathrm{O}_{2}\right)^{15-17}$ or sodium peroxide dihydrate $\left(\mathrm{Na}_{2} \mathrm{O}_{2} \cdot 2 \mathrm{H}_{2} \mathrm{O}\right)^{18,19}$ was formed instead. In addition, these cells exhibited high overpotential during charge, similar to that observed in the $\mathrm{Li}-\mathrm{O}_{2}$ system. Many groups have attempted to determine the reasons for these discrepancies; however, to date, the main cause of the divergence of reactions has not been identified. Janek et al. investigated the effect of different carbon electrodes; Guo et al. and Shao-Horn et al. addressed this issue but observed no critical differences among the cases $^{12,20,21}$.

In this work, we demonstrate the interplay of the diverse reactions in $\mathrm{Na}-\mathrm{O}_{2}$ batteries involving a series of electrochemical and chemical reactions as a function of time. Under systematic control of the operating conditions, we observe that the galvanostatic charge/discharge profiles are sensitively affected by the conditions and durations of the electrochemical operations. It is also revealed that the electrochemically formed $\mathrm{NaO}_{2}$ is unstable and degrades into $\mathrm{Na}_{2} \mathrm{O}_{2} \cdot 2 \mathrm{H}_{2} \mathrm{O}$ in the absence of an applied current. The spontaneous dissolution and ionization of $\mathrm{NaO}_{2}$ liberates the free $\mathrm{O}_{2}^{-}$in the electrolyte and promotes side reactions involving the formation of $\mathrm{Na}_{2} \mathrm{O}_{2} \cdot 2 \mathrm{H}_{2} \mathrm{O}$. On the basis of these observations, we propose reaction mechanisms of $\mathrm{Na}-\mathrm{O}_{2}$ batteries under various operating conditions. This report is the first to reveal the relationships among the different discharge products observed in $\mathrm{Na}-\mathrm{O}_{2}$ batteries, which broadens our understanding of the electrochemical and chemical reactions in $\mathrm{Na}-\mathrm{O}_{2}$ batteries. Furthermore, these discussions may offer insight and guidance to the metal-air battery community in terms of regulating the kinetics of the intertwined reactions.

\section{Results}

Electrochemical profile depending on the operating condition. To address the previous conflicting results on the discharge products and overpotentials of $\mathrm{Na}-\mathrm{O}_{2}$ cells, we carefully assessed the effects of operating parameters on the resulting electrochemical profiles. Among the various parameters examined (Supplementary Figs 1-3 and Supplementary Notes 1-3), we observed that the charge/discharge profiles were most sensitively affected by the applied current and rest time between the discharge and charge, which was analogous to the report by Yadegari et al. as a function of discharge current or limited capacities ${ }^{19}$. Figure 1 presents and compares the electrochemical profiles obtained under various conditions. Although the discharge profiles are similar, with a single plateau at $\sim 2.1 \mathrm{~V}$, there are roughly three different charging plateaus observed at (i) $\sim 2.5 \mathrm{~V}$, (ii) $\sim 3.0 \mathrm{~V}$ and (iii) $3.8 \mathrm{~V}$, which agree with recent reports under certain settings ${ }^{19,20}$. However, the relative lengths of each plateau markedly vary under differing operating conditions. For the cases of controlled discharge currents followed by a constant current charging in Fig. 1a, it was observed that the length of the lower plateau $(\sim 2.5 \mathrm{~V})$ in the charge profiles was reduced as the applied discharge current decreased from 0.5 to $0.02 \mathrm{~mA}$. However, the lengths of the plateaus at higher voltages, that is, $\sim 3.0$ and $3.8 \mathrm{~V}$, were substantially increased, resulting in an overall larger overpotential. Similar behaviours were observed in Fig. 1b when varying the charge currents after a constant current discharge. With the lower applied charge currents, the cell exhibited a higher charging overpotential with shortened plateau length at $2.5 \mathrm{~V}$. This result contrasts with the general observation that slow charging/discharging of electrochemical cells results in a voltage close to the equilibrium potential, thereby resulting in smaller overpotentials. In addition, this result strongly indicates that the different discharge products might undergo the charging process at each case. Notably, the shapes of the electrochemical charge profiles provide important clues to determine the discharge products of $\mathrm{Na}-\mathrm{O}_{2}$ reactions ${ }^{19,22}$. Even though the discharge products should be identical for the cases of the same protocol of discharge, each charge profile was distinct with different charge currents. This finding implies that the initial discharge products are gradually transformed into other phases during the charge process via time-dependent reactions. To verify whether this transformation occurs via an electrochemical or chemical reaction, we also controlled the rest time between the discharge and charge processes. As observed in Fig. 1c, the lowest voltage region in the charge profiles systematically decreases on increasing the rest time from 0 to $12 \mathrm{~h}$. The change in the electrochemical profile in the absence of the applied current clearly indicates that the time-dependent chemical reactions occurred during the rest period, affecting the subsequent charging. This behaviour was also confirmed in similar tests for the higher charging currents with the resting time after the discharge, which revealed the growth of the charge polarizations on increasing the rest time (Supplementary Fig. 1).

The time-dependent chemical reactions can be more clearly visualized by plotting all the voltage profiles as a function of the time. Figure 1d-j illustrates the voltage evolution of each cell after the completion of the discharge at different operating conditions. The first inflection points of the voltage profiles at charge (indicated with arrows) occur at $\sim 10 \mathrm{~h}$ regardless of the rest or charge protocols. This result indicates that a specific time of $\sim 10 \mathrm{~h}$ is required before observing a change of the profile, which hints at the kinetics of the chemical reactions.

Time-resolved characterization of discharge products. To confirm the time-dependent phase transformation of the discharge products via chemical reaction in $\mathrm{Na}-\mathrm{O}_{2}$ cells, we 

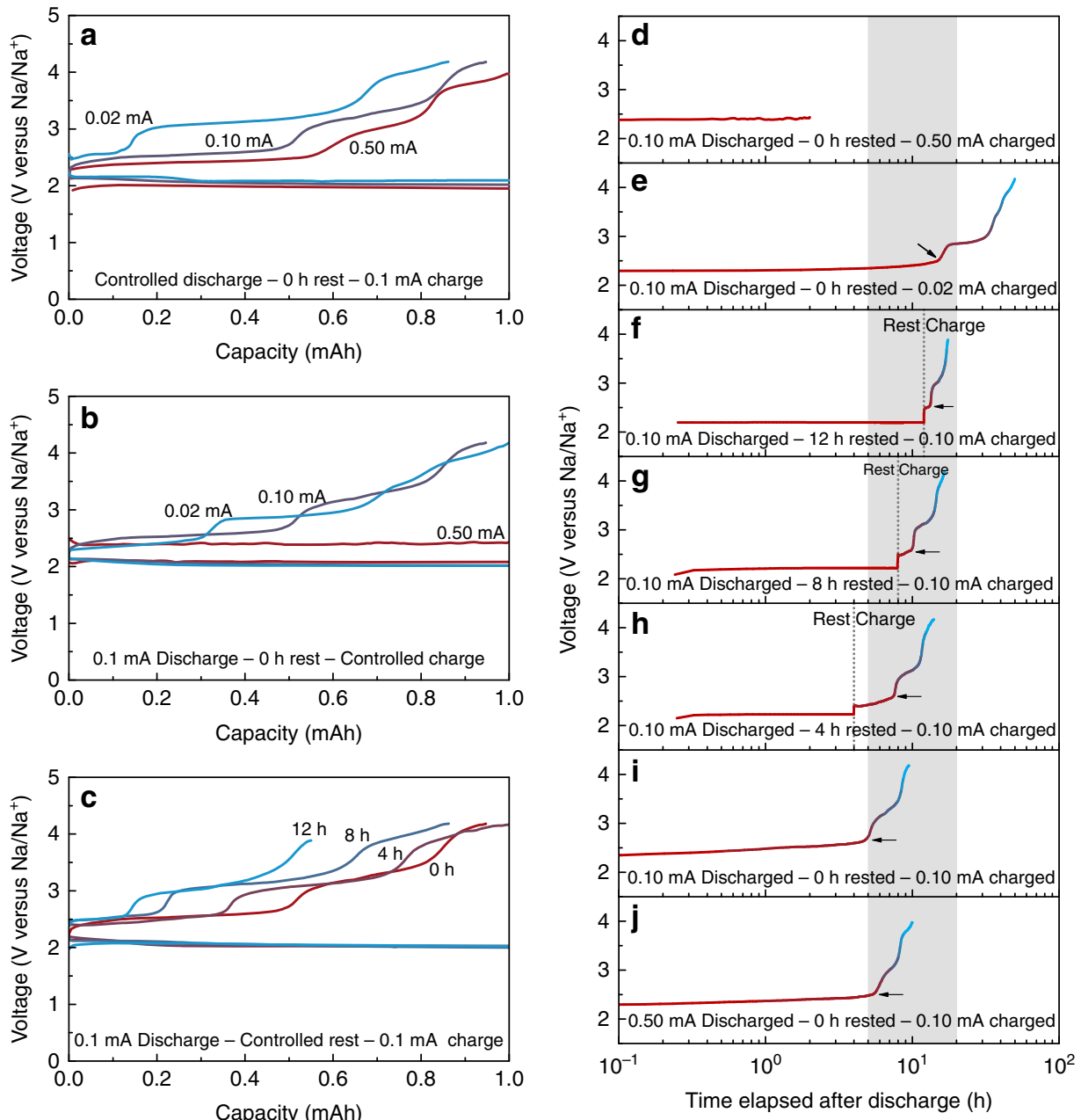

Figure 1 | Electrochemical charge/discharge profiles of $\mathbf{N a}-\mathbf{O}_{\mathbf{2}}$ cells under various operating conditions. (a) Discharge currents of $0.02,0.1$ and $0.5 \mathrm{~mA}$; (b) charge currents of $0.02,0.1$ and $0.5 \mathrm{~mA}$ and (c) rest times of $0,4,8$ and $12 \mathrm{~h}$. All the cells utilized a limited capacity of $1.0 \mathrm{mAh}$. (d-j) Representations of voltage profiles as a function of time corresponding to a-c. The shaded area indicates that range of the first points of the polarized charge potentials.

characterized the discharge products in air electrodes as a function of the rest time. The highly crystalline $\mathrm{NaO}_{2}$ was observed directly after the discharge with no other phases, as demonstrated in the X-ray diffraction spectra (Fig. 2a,b) ${ }^{11}$. However, after being aged for several hours, the $\mathrm{NaO}_{2}$ peak slowly diminished, whereas the characteristic peak of $\mathrm{Na}_{2} \mathrm{O}_{2} \cdot 2 \mathrm{H}_{2} \mathrm{O}$ began to appear and grew. After $12 \mathrm{~h}$ of resting, the initial discharge product was completely transformed into $\mathrm{Na}_{2} \mathrm{O}_{2} \cdot 2 \mathrm{H}_{2} \mathrm{O}$. It should be noted that $\mathrm{Na}_{2} \mathrm{O}_{2} \cdot 2 \mathrm{H}_{2} \mathrm{O}$ has often been regarded as a main discharge product in previous reports of $\mathrm{Na}-\mathrm{O}_{2}$ batteries ${ }^{18-20}$. Recently, Ortiz-Vitoriano et al. reported that $\mathrm{NaO}_{2}$ could convert to $\mathrm{Na}_{2} \mathrm{O}_{2} \cdot 2 \mathrm{H}_{2} \mathrm{O}$ on exposure to the ambient air during the characterization at room temperature ${ }^{21}$. However, our data show that such transformation occurs in the electrochemical cells by the intrinsic dissolving characteristics of $\mathrm{NaO}_{2}$ in the electrolyte even without the exposure to the ambient atmosphere. Remarkably, the time taken for the discharge product to completely transform into $\mathrm{Na}_{2} \mathrm{O}_{2} \cdot 2 \mathrm{H}_{2} \mathrm{O}$ coincides with the timeline of Fig. $1 \mathrm{~d}-\mathrm{j}$, which shows the inflection of the voltage rising after $\sim 10 \mathrm{~h}$. When we analysed the phases of the discharge products as a function of the applied discharge currents (Supplementary Fig. 4), it was also observed that the $\mathrm{NaO}_{2} / \mathrm{Na}_{2} \mathrm{O}_{2} \cdot 2 \mathrm{H}_{2} \mathrm{O}$ ratio decreased with the lower operating current, which is consistent with the time-dependent transformation of the discharge products.
Raman spectroscopy results confirmed that the initial $\mathrm{NaO}_{2}$ discharge products gradually transformed into $\mathrm{Na}_{2} \mathrm{O}_{2} \cdot 2 \mathrm{H}_{2} \mathrm{O}$ with resting. In Fig. 2c, the two distinct peaks of $\mathrm{NaO}_{2}$ and $\mathrm{Na}_{2} \mathrm{O}_{2} \cdot 2 \mathrm{H}_{2} \mathrm{O}$ are detected along with the characteristic bands $(\mathrm{D} / \mathrm{G})$ of the carbon electrode. The Raman signals at 1,156 and $1,136 \mathrm{~cm}^{-1}$ are attributed to the $\mathrm{O}-\mathrm{O}$ stretch bonding in $\mathrm{NaO}_{2}$ and $\mathrm{Na}_{2} \mathrm{O}_{2} \cdot 2 \mathrm{H}_{2} \mathrm{O}$, respectively ${ }^{21}$. The systematic change in the relative ratios of $\mathrm{NaO}_{2}$ and $\mathrm{Na}_{2} \mathrm{O}_{2} \cdot 2 \mathrm{H}_{2} \mathrm{O}$ with time is clearly illustrated in Fig. 2d, which agrees well with the results in Fig. 2b. The phase transition of $\mathrm{NaO}_{2}$ to proton-containing $\mathrm{Na}_{2} \mathrm{O}_{2} \cdot 2 \mathrm{H}_{2} \mathrm{O}$ indicates a source of protons in the electrochemical cell. Considering the low water content in the electrolyte used for the cell (less than $\sim 5$ p.p.m.), which is insufficient to form the phase (calculations provided in Supplementary Note 4$)^{21,23,24}$, the protons are likely delivered from other sources such as the electrolyte solvent. As we could expect, the rechargeability of $\mathrm{Na}-\mathrm{O}_{2}$ cell was better for the highly biased electrochemical conditions coupled with the low polarized charge profile (Supplementary Fig. 3), which is attributed to the electrochemical formation and decomposition of $\mathrm{NaO}_{2}$ as shown in Supplementary Fig. 5. However, the electrochemical reversibility with the three-stepped charge profile shown from $\mathrm{Na}_{2} \mathrm{O}_{2} \cdot 2 \mathrm{H}_{2} \mathrm{O}$ was relatively worse compared with the former conditions. The proposed transformation mechanism will be discussed in detail later. 

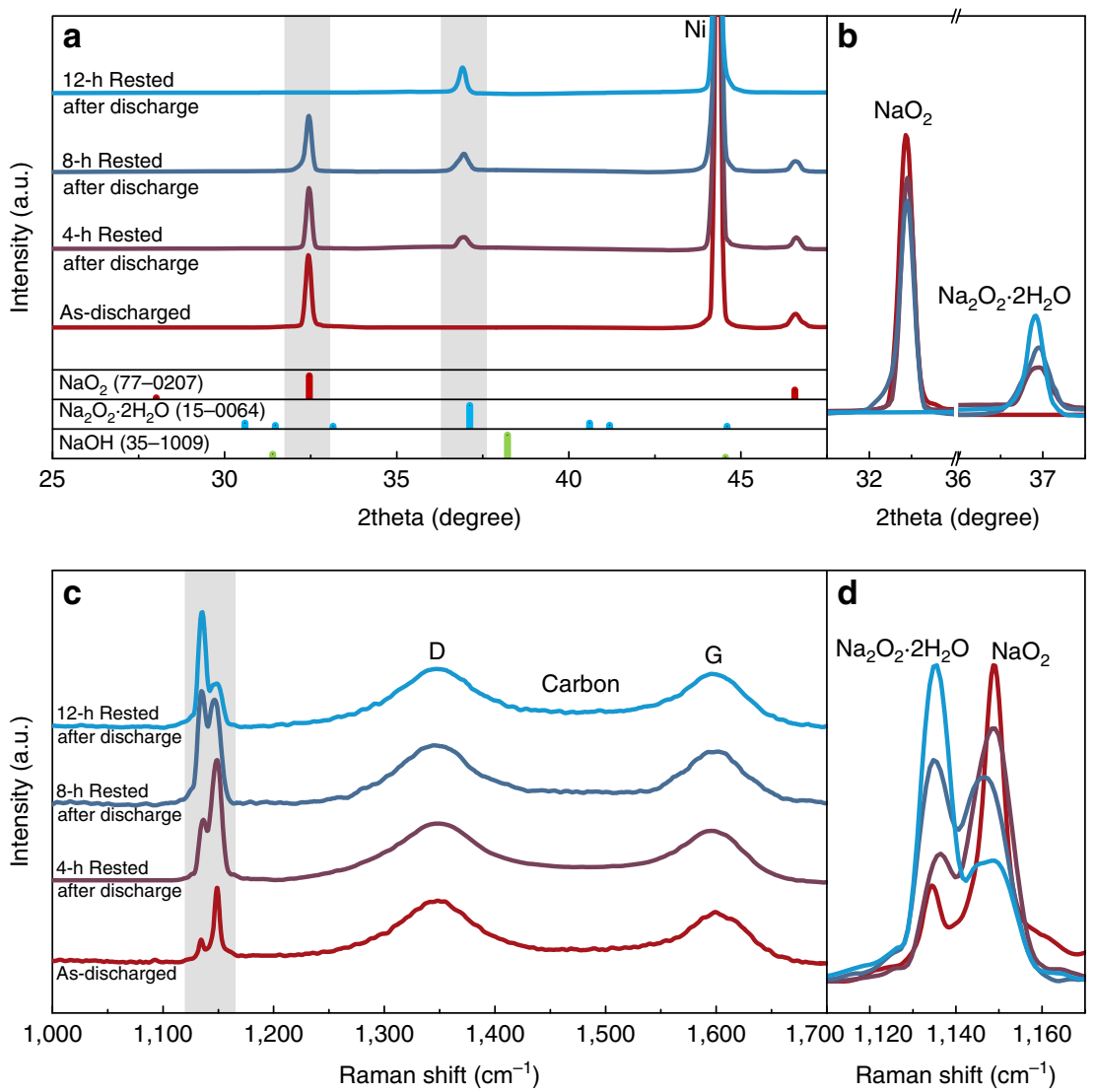

Figure 2 | Time-resolved characterization showing the phase transitions of the discharge products of the $\mathbf{N a}-\mathbf{O}_{\mathbf{2}}$ cells. (a,b) X-ray diffraction spectra of the discharged cathodes of $\mathrm{Na}-\mathrm{O}_{2}$ batteries with rest times of $0,4,8$ and $12 \mathrm{~h}$. (c,d) Raman spectra of the discharged cathodes of $\mathrm{Na}-\mathrm{O}_{2}$ batteries with rest times of $0,4,8$ and $12 \mathrm{~h}$.

Morphological change of discharge products over time. To visualize the transition process, we examined the morphologies of the discharge products at different rest times within $12 \mathrm{~h}$. In Fig. 3a, well-defined micron-sized cubic $\mathrm{NaO}_{2}$ was observed immediately after the discharge, which agrees with the observation of Hartmann et al. ${ }^{11}$. However, the edges of the cubes became significantly dull, and the overall shapes of the cubes obtained were smudged during the rest period (Fig. 3b,c). At the end of the rest period, the cubic crystallites completely disappeared, and rod-shaped microparticles began to appear, which resemble the $\mathrm{Na}_{2} \mathrm{O}_{2} \cdot 2 \mathrm{H}_{2} \mathrm{O}$ in a previous report ${ }^{19}$. This morphological change suggests the disappearance of $\mathrm{NaO}_{2}$ and the subsequent appearance of $\mathrm{Na}_{2} \mathrm{O}_{2} \cdot 2 \mathrm{H}_{2} \mathrm{O}$ in the cell during the rest period. Moreover, this finding implies that the transformation does not occur via a conventional solid-state or interfacial reaction between $\mathrm{NaO}_{2}$ and the electrolyte to form $\mathrm{Na}_{2} \mathrm{O}_{2} \cdot 2 \mathrm{H}_{2} \mathrm{O}$, which would not involve significant morphological change. Rather, it is likely to be a solutionmediated process through dissolution and nucleation ${ }^{25-27}$.

Dissolution and ionization of $\mathrm{NaO}_{2}$. We investigated the possibility of the dissolution of the solid $\mathrm{NaO}_{2}$ phase in the electrolyte using electron spin resonance (ESR) spectroscopy, which is useful for detecting the magnetic responses of the unpaired electrons in radicals such as $\mathrm{O}_{2}^{-}$(ref. 28). Surprisingly, as observed in Fig. 4a, with the simple immersion of the predischarged cathodes, the ESR signal evolved within $10 \mathrm{~min}$ from the fresh electrolyte, indicating the presence of $\mathrm{O}_{2}^{-}$. To avoid any effect of the remaining oxygen from the disassembled $\mathrm{Na}-\mathrm{O}_{2}$ cells, the pre-discharged cathodes were washed with fresh electrolyte before the measurement, which led to an identical result. The calculated $g$-value of 2.0023 for the observed ESR signal corresponds well with the theoretical value of the unpaired electron in free $\mathrm{O}_{2}^{-}$(ref. 29). The solubility of $\mathrm{NaO}_{2}$ in the electrolyte was roughly estimated to be $\sim 187 \mathrm{mM}$, which is in the similar order with the report by Schechter et al. ${ }^{30}$, but has a relatively large discrepancy to the report by Hartmann et al. ${ }^{31}$. This discrepancy might be mainly due to the additional chemical reactions involving the precipitation of solid $\mathrm{Na}_{2} \mathrm{O}_{2} \cdot 2 \mathrm{H}_{2} \mathrm{O}$. The detection of $\mathrm{O}_{2}^{-}$indicates that the $\mathrm{NaO}_{2}$ is soluble in the ether-based electrolytes, which was also expected from the literatures with the electrochemical determinations $21,24,31$. Furthermore, this behaviour is analogous to highly soluble $\mathrm{LiO}_{2}$ in the solvatable conditions of $\mathrm{Li}-\mathrm{O}_{2}$ batteries ${ }^{23,32}$. More importantly, the dissolution can immediately lead to the ionization of $\mathrm{NaO}_{2}$, liberating $\mathrm{O}_{2}^{-}$, the consequences of which will be discussed later.

Figure $4 \mathrm{~b}$ shows that the peak widths of the ESR signals increased slightly with time. The broadening indicates the energy exchange of the spin with the local environments via spin-spin relaxation or spin-lattice relaxation ${ }^{28}$. This interaction supports the time-dependent chemical reactions associated with the dissolved $\mathrm{O}_{2}^{-}$with its neighbouring electrolyte solvent. The intensity of the $\mathrm{O}_{2}^{-}$signal is the highest $\sim 20 \mathrm{~min}$ after the immersion and exponentially decreases over time, indicating the instability of $\mathrm{O}_{2}^{-}$in the electrolyte ${ }^{33}$. From this behaviour, we could derive that it was a pseudo-first-order reaction that mainly relates with the concentration of $\mathrm{O}_{2}^{-}$. On the basis of the exponential fitting of the relative intensity of ESR signals, the pseudo-first-order rate constant of $\mathrm{H}^{+}$abstraction was obtained as $\sim k^{\prime} \approx 0.560$, and its corresponding half-life was 

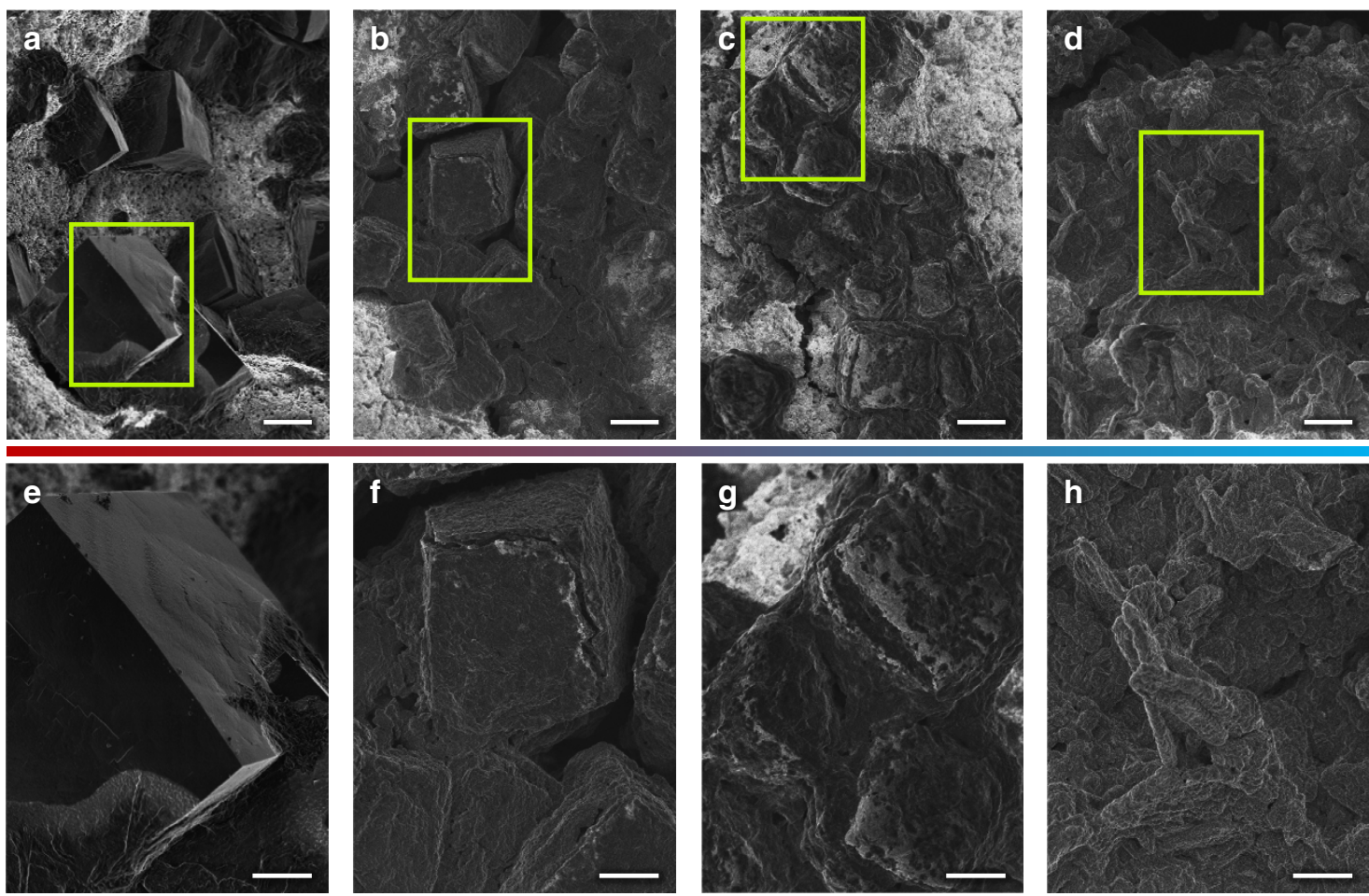

Figure 3 | Time-resolved examinations of the morphology of discharge products on the cathodes of $\mathbf{N a}-\mathbf{O}_{\mathbf{2}}$ cells. (a-d) Morphology of the discharge products of $\mathrm{Na}-\mathrm{O}_{2}$ cells (scale bar, $10 \mu \mathrm{m}$ ). (e-h) Corresponding magnified scanning electron microscopy micrographs (scale bar, $5 \mu \mathrm{m}$ ); $(\mathbf{a}, \mathbf{e})$ as-discharged, $(\mathbf{b}, \mathbf{f})$ 4-h rest after discharge, $(\mathbf{c}, \mathbf{g})$ 8-h rest after discharge and (d,h) 12-h rest after discharge.

estimated as $\sim t_{1 / 2}=\ln (2) / k^{\prime} \approx 1.24 \mathrm{~h}$ (the detailed derivation is in Supplementary Note 5). Figure $4 \mathrm{c}$ reveals, however, that the time-dependent decay of the intensity is relatively sluggish compared with the intrinsic lifetime of normal $\mathrm{O}_{2}^{-}$. Typically, the half-life of $\mathrm{O}_{2}^{-}$is $\sim 1-15 \mathrm{~min}$ because of its high reactivity and instability ${ }^{34}$. The abnormally long half-life in the electrolyte $(\sim 1.24 \mathrm{~h})$ in our case is believed to occur because $\mathrm{O}_{2}^{-}$is continuously generated with the dissolution of $\mathrm{NaO}_{2}$. The ESR signal completely vanished after $\sim 8 \mathrm{~h}$, which is slightly faster than the time required for the formation of $\mathrm{Na}_{2} \mathrm{O}_{2} \cdot 2 \mathrm{H}_{2} \mathrm{O}$ in Fig. 2. Despite the evolution of $\mathrm{O}_{2}^{-}$, the overall signal decay might be induced from the relatively dominant $\mathrm{H}^{+}$abstraction due to the reactivity of $\mathrm{O}_{2}^{-}$. This gap in the kinetics might originate from the time required to form the $\mathrm{Na}_{2} \mathrm{O}_{2} \cdot 2 \mathrm{H}_{2} \mathrm{O}$ phase from the $\mathrm{O}_{2}^{-}$.

To understand the dissolution and ionization behaviour of $\mathrm{NaO}_{2}$, the solvation energies of various alkali-metal superoxides and peroxides were calculated for comparison using firstprinciple calculations with the series of dielectric constant from 7 to 30 . Figure $4 \mathrm{~d}$ reveals that generally the superoxide exhibits a lower solvation energy than the peroxide for both lithium and sodium compounds. This result is consistent with our result of $\mathrm{NaO}_{2}$ dissolution and the recent experimental findings for $\mathrm{Li}-\mathrm{O}_{2}$ batteries, which indicated that $\mathrm{LiO}_{2}$ is found mostly as soluble intermediates in the electrolyte in contrast to the solid phase of $\mathrm{Li}_{2} \mathrm{O}_{2}$ (refs 23,32). In addition, it is notable that the solvation energy of the sodium phases was significantly lower than that of the lithium phases, which is attributed to the weaker Lewis acidity of the Na cation compared with that of the Li cation in the polar solvent ${ }^{35,36}$. However, for the solvents with substantially lower dielectric constant $(\varepsilon=\sim 7)$, the dissolution is not favourable even in $\mathrm{NaO}_{2}$. Molecular dissolution energies of $\mathrm{NaO}_{2}$ in model solvents are $\sim 0.6 \mathrm{eV}$, which roughly corresponds to one molecule dissolution among $10^{10}$ formula units of $\mathrm{NaO}_{2}$. On the other hand, it markedly diminishes to $0.17 \mathrm{eV}$ (one molecule among $10^{3}$ formula units of $\mathrm{NaO}_{2}$ ) in $\varepsilon=30$ (ref. 37). Note that, for the low dielectric constant solvents, dielectric constant of the solution sensitively increases with increasing salt concentration, which can result in higher solution dielectric constant than that of the pure solvent ${ }^{38}$. Therefore, it is expected that the dissolution of $\mathrm{NaO}_{2}$ can occur when salts are present in the electrolyte, which is consistent with the observation of $\mathrm{O}_{2}^{-}$in the ESR analysis. It also is noted that even with the dissolving characteristics of $\mathrm{NaO}_{2}$, the crystallization of $\mathrm{NaO}_{2}$ is possible in the normal discharging conditions with the supersaturation of localized reactants such as $\mathrm{Na}^{+}$and $\mathrm{O}_{2}^{-}$(refs 21,31,39,40). In the other case where the supply of the reactants such as $\mathrm{Na}^{+}$is limited, for example, in the absence of the applied voltage, the dissolution and ionization might dominate, giving rise to the formation of $\mathrm{Na}_{2} \mathrm{O}_{2} \cdot 2 \mathrm{H}_{2} \mathrm{O}$ as a discharge product.

Proposed mechanism of $\mathrm{Na}-\mathrm{O}_{2}$ batteries. On the basis of the previous reports and our new findings, we propose a mechanism that describes the electrochemical and chemical reactions in $\mathrm{Na}-\mathrm{O}_{2}$ systems in Fig. 5. The well-established discharge process ${ }^{11}$ can be illustrated with the reduction of an $\mathrm{O}_{2}$ molecule into $\mathrm{O}_{2}^{-}$, which reacts with $\mathrm{Na}^{+}$to form $\mathrm{NaO}_{2}$ (Reaction 1), and the charge process is the reverse reaction (Reaction 2). After or during the discharge, the $\mathrm{NaO}_{2}$ is prone to dissolution and ionization into the electrolyte based on the solvating energy $\left(\Delta G_{\text {sol }}\right)$ in the solvent (Reaction 3$)^{32}$. The dissolution of $\mathrm{NaO}_{2}$ generates $\mathrm{O}_{2}^{-}$, which can degrade the surrounding molecules because of its chemical instability. Typically, the liberated $\mathrm{O}_{2}^{-}$is a strong reagent for the abstraction of $\mathrm{H}^{+}$from the electrolyte solvents (Reaction 4$)^{9}$, and the degree of $\mathrm{H}^{+}$abstraction ${ }^{41,42}$ is determined by the acid-dissociation constant $\left(\mathrm{p} K_{\mathrm{a}}\right)$ of the solvent. Some hydroperoxyl radicals $\left(\mathrm{HO}_{2}\right)$ might be formed during this process, resulting in the nucleophilic attack of the $\mathrm{H}^{+}$-lost solvent (Reaction 5) ${ }^{43}$. However, the evolution of $\mathrm{HO}_{2}$ can be 

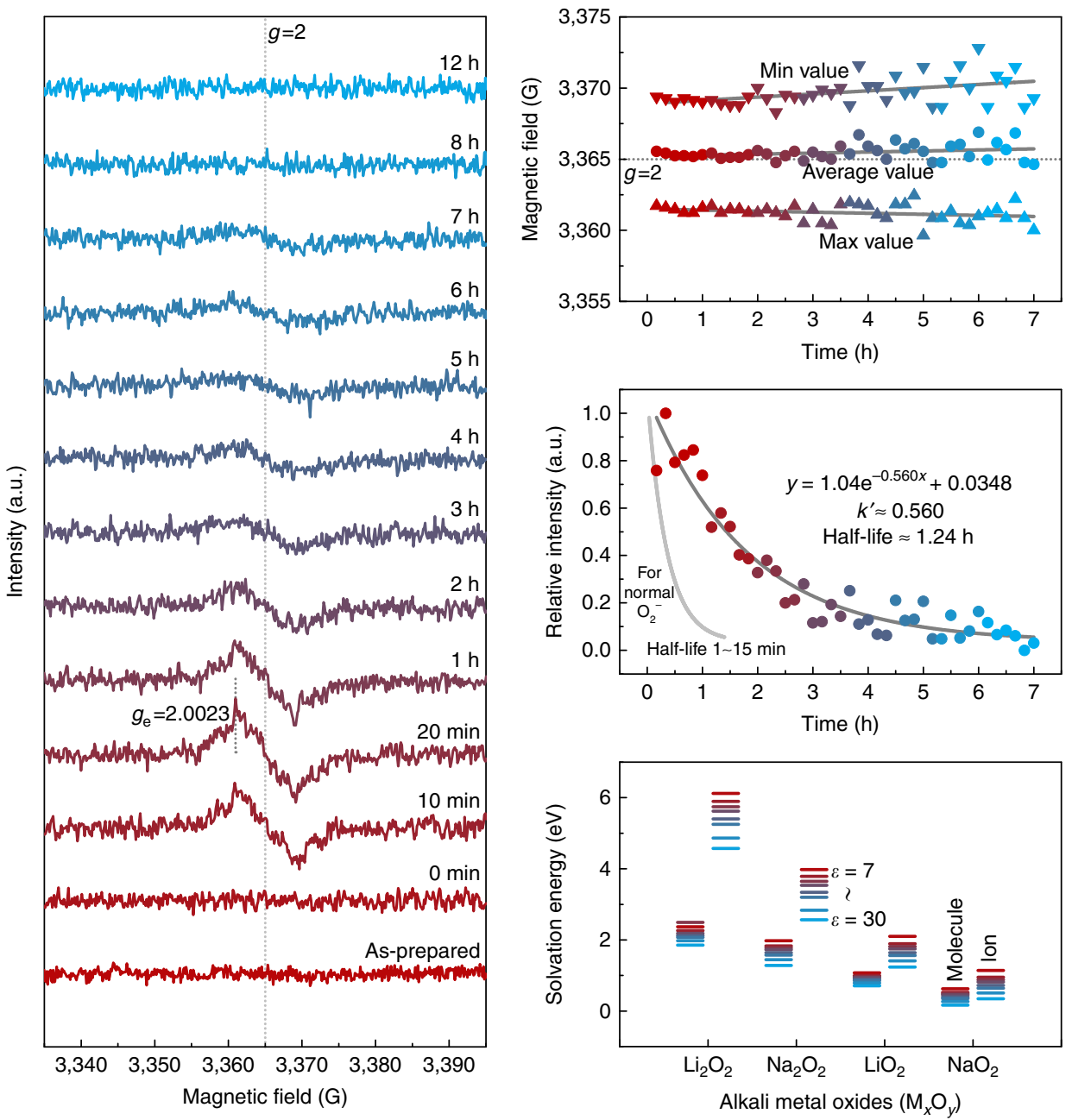

Figure 4 | ESR analysis and theoretical calculations of the dissolution and ionization of $\mathbf{N a O}_{\mathbf{2}}$ into the electrolyte. (a) Time-dependent ESR measurements for the fresh electrolytes $\left(0.5 \mathrm{M} \mathrm{NaCF}_{3} \mathrm{SO}_{3}\right.$ in diethylene glycol dimethyl ether) with soaking of the pre-discharged cathode without any aging. (b) Maximum, minimum and average values of ESR signals as a function of time. (c) Exponential decay of ESR signals and the common trend line of $\mathrm{O}_{2}^{-}$. (d) Calculations of the solvation energy for several alkali-metal superoxides and peroxides with the various dielectric constants $(\varepsilon=7 \sim 30)$.

helpful in promoting the solution-mediated discharge/charge process as recently reported by Xia $e^{2}$ al. $^{24}$. Nevertheless, in a circumstance where the dissolution/ionization of $\mathrm{NaO}_{2}$ is dominant, the liberation of $\mathrm{O}_{2}^{-}$is overwhelmingly larger than a possible $\mathrm{HO}_{2}$ formation, inducing the $\mathrm{H}^{+}$abstraction from the neighbouring electrolyte solvent. Meanwhile, the solvent undergoes oxidative decompositions to produce byproducts such as carbon dioxide $\left(\mathrm{CO}_{2}\right)$, water $\left(\mathrm{H}_{2} \mathrm{O}\right)$ and hydroxyl anions $\left(\mathrm{OH}^{-} \text {; Reaction } 6\right)^{9}$. It is also possible that the coupling of $\mathrm{HO}_{2}$ leads to disproportionation into hydrogen peroxide $\left(\mathrm{H}_{2} \mathrm{O}_{2}\right)$ and $\mathrm{O}_{2}$ (Reaction 7) ${ }^{44}$. In the presence of both $\mathrm{Na}^{+}$and $\mathrm{OH}^{-}$, which is effectively the dissolution state of sodium hydroxide $(\mathrm{NaOH})$, a solid crystallite of $\mathrm{NaOH}$ can precipitate with a higher concentration of $\mathrm{OH}^{-}$produced. Further reaction between $\mathrm{NaOH}$ and $\mathrm{H}_{2} \mathrm{O}_{2}$ from Reaction 7 leads to the formation of $\mathrm{Na}_{2} \mathrm{O}_{2} \cdot 2 \mathrm{H}_{2} \mathrm{O}$ via peroxo-hydroxylation, whose reverse reaction is well known (Reaction 8$)^{45}$. To support our proposed reaction mechanism, we chose several intermediate reactions that should be verified according to the reaction model in the Supplementary Information. Supplementary Figs 6-9 demonstrate that $\mathrm{O}_{2}^{-}$plays an important role after the dissolution of $\mathrm{NaO}_{2}$ in converting the discharge product to $\mathrm{Na}_{2} \mathrm{O}_{2} \cdot 2 \mathrm{H}_{2} \mathrm{O}$ via degradation of the electrolyte involving $\mathrm{OH}^{-}$ and $\mathrm{H}_{2} \mathrm{O}_{2}$. These identifications strongly support the proposed mechanism of competing electrochemical and following chemical reactions in $\mathrm{Na}-\mathrm{O}_{2}$ batteries. The detailed discussions are provided in Supplementary Notes 6-9. The reaction equations are summarized below:

Discharge/charge : $\mathrm{Na}^{+}+\mathrm{O}_{2}+\mathrm{e}^{-} \leftrightarrow \mathrm{NaO}_{2}$

Dissolution/ionization : $\mathrm{NaO}_{2} \rightarrow \mathrm{Na}^{+}+\mathrm{O}_{2}^{-}$

Proton abstraction: $\mathrm{HA}+\mathrm{O}_{2}^{-} \rightarrow \mathrm{A}^{-}+\mathrm{HO}_{2}$

Disproportionation : $2 \mathrm{HO}_{2} \rightarrow \mathrm{H}_{2} \mathrm{O}_{2}+\mathrm{O}_{2}$

Oxidative decomposition : $\mathrm{A}^{-}+\mathrm{HO}_{2} \rightarrow \mathrm{CO}_{2}, \mathrm{H}_{2} \mathrm{O}, \mathrm{OH}^{-}$

Peroxo-hydroxylation : $2 \mathrm{Na}^{+}+2 \mathrm{OH}^{-}+\mathrm{H}_{2} \mathrm{O}_{2} \rightarrow \mathrm{Na}_{2} \mathrm{O}_{2} \cdot 2 \mathrm{H}_{2} \mathrm{O}$

It is noteworthy that a similar behaviour has been recently reported for reactions in $\mathrm{Li}-\mathrm{O}_{2}$ batteries. The solvating environment was demonstrated to alter the stability of the intermediates, such as a lithium superoxide $\left(\mathrm{LiO}_{2}\right)$, thus affecting the overall reaction paths ${ }^{23,32}$. $\mathrm{LiO}_{2}$ is a precedent phase with the direct reaction of a $\mathrm{Li}$ cation and superoxide anion $\left(\mathrm{O}_{2}^{-}\right)$, which readily decomposes into lithium peroxide $\left(\mathrm{Li}_{2} \mathrm{O}_{2}\right)$ via either 


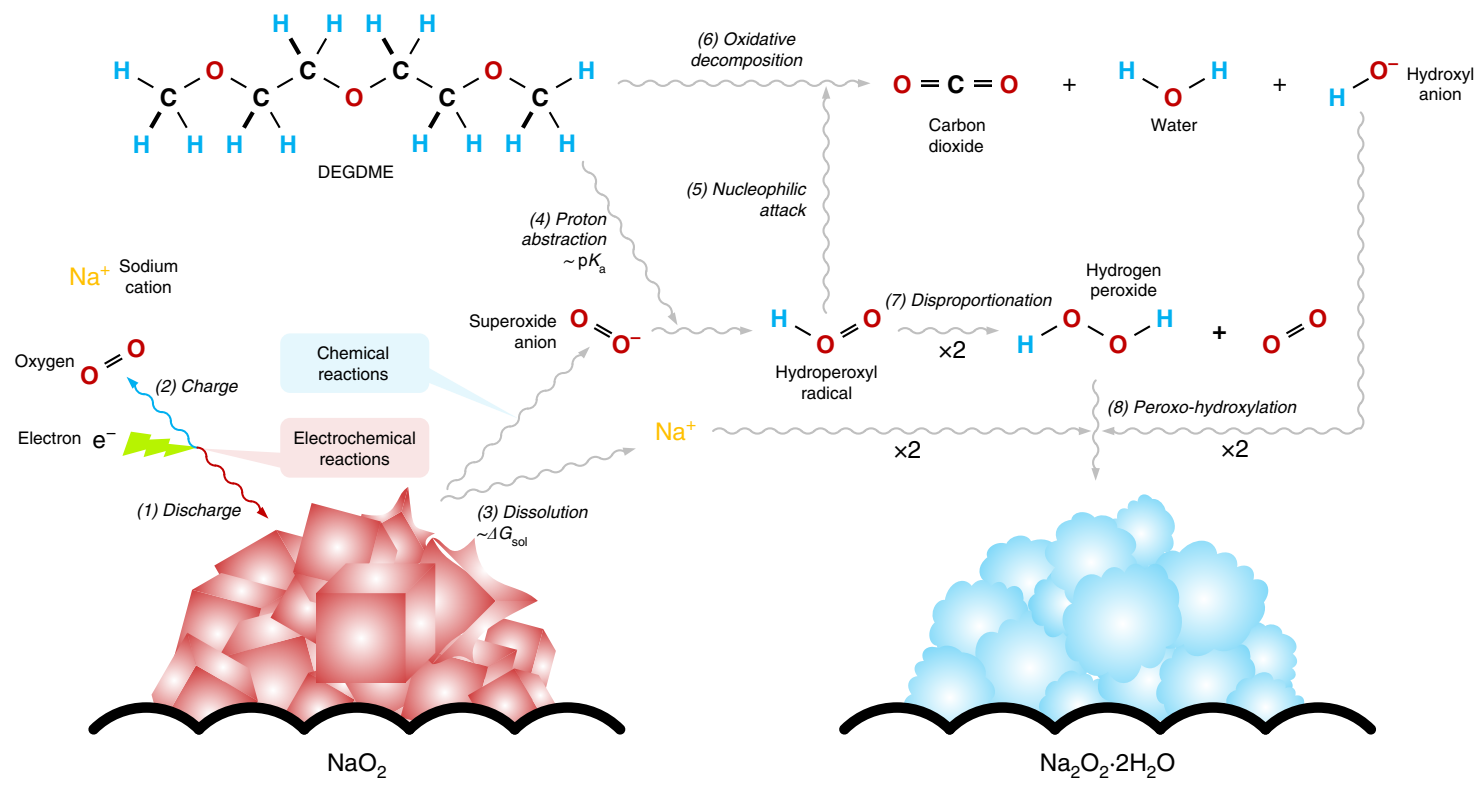

Figure 5 | Schematic of the proposed mechanism illustrating the electrochemical and chemical reactions under various operating conditions. For the electrochemical reaction, $\mathrm{NaO}_{2}$ is formed and decomposed during discharge/charge (Reactions 1 and 2). For the chemical reaction, $\mathrm{NaO}_{2}$ is dissolved and ionized into the electrolyte (Reaction 3), which promotes the undesired degradation of the electrolyte (Reactions $4-6$ ). $\mathrm{Na}_{2} \mathrm{O}_{2} \cdot 2 \mathrm{H}_{2} \mathrm{O}$ is formed during the subsequent chemical reactions (Reactions 7 and 8 ).

an electrochemical surface reaction or disproportionation ${ }^{23,32}$. Although $\mathrm{LiO}_{2}$ is known to be unstable 46,47 , it was recently demonstrated that $\mathrm{LiO}_{2}$ might be dissolved into the electrolyte and aid in the formation of the toroidal $\mathrm{Li}_{2} \mathrm{O}_{2}$ via a solution reaction under highly solvating conditions ${ }^{23} \cdot \mathrm{NaO}_{2}$ shares this dissolving nature with $\mathrm{LiO}_{2}$ even though the thermodynamic stability of $\mathrm{NaO}_{2}$ warrants its formation as a discharge product. The significant dissolution of $\mathrm{NaO}_{2}$ supports the conclusion that the dominant reaction in $\mathrm{Na}-\mathrm{O}_{2}$ batteries relies on the solutionmediated reactions of nucleation and growth of $\mathrm{NaO}_{2}$ (refs 21,24,31) and implies that the capacities and morphology of the reaction products would be greatly affected by the energetics of $\mathrm{NaO}_{2}$ under various conditions (such as different electrolytes and current rates). This is also supplemented with the recently reported observations ${ }^{21,31}$ and operating mechanism ${ }^{24}$ in terms of the various states of electrochemical and chemical reactions.

\section{Discussion}

We successfully demonstrated the interplay of the diverse competing reactions in $\mathrm{Na}-\mathrm{O}_{2}$ batteries. The time-dependent chemical reactions were identified as being triggered from the dissolution and ionization of the electrochemically formed $\mathrm{NaO}_{2}$ in the electrolyte. The liberated $\mathrm{O}_{2}^{-}$reacts with the electrolyte solvent to form $\mathrm{Na}_{2} \mathrm{O}_{2} \cdot 2 \mathrm{H}_{2} \mathrm{O}$ following a series of intermediate steps. The $\mathrm{Na}_{2} \mathrm{O}_{2} \cdot 2 \mathrm{H}_{2} \mathrm{O}$ in the air electrode requires a higher energy for the decomposition, which leads to the increased charge overpotential and irreversibility of $\mathrm{Na}-\mathrm{O}_{2}$ cells. This report is the first to correlate the electrochemical and chemical reactions with the operating conditions in $\mathrm{Na}-\mathrm{O}_{2}$ batteries, and our findings concerning the relationships among different phases resolve the conflicting observations of different discharge products in previous $\mathrm{Na}-\mathrm{O}_{2}$ batteries. To prepare a better performing $\mathrm{Na}-\mathrm{O}_{2}$ battery, a strategy to prevent the transformation of $\mathrm{NaO}_{2}$ into $\mathrm{Na}_{2} \mathrm{O}_{2} \cdot 2 \mathrm{H}_{2} \mathrm{O}$ while still allowing the solution-mediate discharge reaction is necessary. We hope that the findings of this study can provide a basis for researchers to navigate and direct the reactions in $\mathrm{Na}-\mathrm{O}_{2}$ batteries to achieve high efficiency and rechargeability.

\section{Methods}

Cell assembly and galvanostatic cycling of $\mathbf{N a}-\mathbf{O}_{2}$ cells. The carbon cathode was prepared by casting Ketjen Black carbon paste and polytetrafluoroethylene (60 wt\% emersion in water, Sigma-Aldrich) with a mass ratio of 9:1 in a solution of isopropanol (>99.7\%, Sigma-Aldrich) and N-methyl-2-pyrrolidone (99.5\%, anhydrous, Sigma-Aldrich) with a volume ratio of 1:1 on Ni mesh current collectors. The carbon-coated $\mathrm{Ni}$ mesh was dried at $120^{\circ} \mathrm{C}$ and heated at $400{ }^{\circ} \mathrm{C}$ for $4 \mathrm{~h}$ in $\mathrm{Ar}$ to completely remove any residual $\mathrm{H}_{2} \mathrm{O}$ impurities.

All the procedures described below were performed in an Ar-filled glove box $\left(\mathrm{O}_{2}\right.$ level $<0.5$ p.p.m. and $\mathrm{H}_{2} \mathrm{O}$ level $<0.5$ p.p.m.). The $\mathrm{Na}-\mathrm{O}_{2}$ cells were assembled as a Swagelok-type cell with stacking of the $\mathrm{Na}$ metal anode, electrolyte-soaked separators and carbon cathode, which was punched with a half-inch diameter. The $\mathrm{Na}$ metal anode was carefully prepared by milling dry Na metal chunks (ACS Reagent, Sigma-Aldrich) after removing the contaminated surfaces. The electrolyte was prepared with diethylene glycol dimethyl ether (anhydrous, 99.5\%, SigmaAldrich), which contains $0.5 \mathrm{M} \mathrm{NaCF}_{3} \mathrm{SO}_{3}$ (98\%, Sigma-Aldrich). The solvent was dried using $3-\AA \AA$ molecular sieves for over 1 week, and the salt was also kept in a vacuum oven at $180^{\circ} \mathrm{C}$ for the same time before use. The final water content in the electrolyte was less than 10 p.p.m. according to a Karl-Fisher titration measurement. The amount of electrolyte used for the cell was $200 \mu$ l. Two sheets of Celgard 2400 were used as separators. Electrochemical battery tests of the $\mathrm{Na}-\mathrm{O}_{2}$ cells were conducted using a potentio-galvanostat (WonA Tech, WBCS 3000,

Korea). All the cells were relaxed under 770 torr of $\mathrm{O}_{2}$ pressure for $10 \mathrm{~min}$ before the tests. After being saturated with $\mathrm{O}_{2}$ gas, the cells were operated in the closed state with a limited capacity of $1 \mathrm{mAh}$, lower voltage cutoff of $1.6 \mathrm{~V}$ and upper voltage cutoff of $4.2 \mathrm{~V}$. Special protocol based on a pulsed current was applied during the charge to avoid dendritic failure of the Na metal anode. The on/off time ratio of the pulse charge was 1:4 (applying current for $0.5 \mathrm{~s}$ and relaxing for $2 \mathrm{~s}$ ). More details about our charge protocol are provided in Supplementary Figs 10 and 11 and following discussions in Supplementary Note 10.

Characterization of $\mathbf{N a}-\mathrm{O}_{2}$ cells. The discharged cathodes after the different rest times were collected from disassembled $\mathrm{Na}-\mathrm{O}_{2}$ cells and washed with acetonitrile (anhydrous, 99.8\%, Sigma-Aldrich) in a glove box to remove any residual electrolyte. X-ray diffraction spectra of the cathodes were obtained using a Bruker D2Phaser ( $\mathrm{Cu} \mathrm{K \alpha} \lambda=1.5406 \AA)$ with the aid of a specially designed air-tight holder to prevent outer atmospheric contamination. Raman spectra were obtained using a Horiba Jobin-Yvon LabRam Aramis spectrometer (the 514-nm line of an Ar-ion laser was used as the excitation source). The scattered light of the Raman signal was collected in a backscattering geometry using the $\times 50$ microscope objective lens. Field-emission scanning electron microscopy (MERLIN Compact, ZEISS, Germany) was used for the morphological observations after Pt coating. For ESR characterization, the collected powder from the discharged cathodes after rinsing to remove the residual used electrolytes was soaked in fresh electrolyte. After immersing the powdery discharged cathodes, the ESR signal of the electrolytes was 
measured at room temperature using a JEOL JES-TE200 ESR spectrometer every $10 \mathrm{~min}$ for $12 \mathrm{~h}$ using a liquid quartz cell. The microwave $\mathrm{X}$-band frequency was $9.42 \mathrm{GHz}$ at $1-\mathrm{mW}$ power.

Theoretical calculations of solvation energy. First-principles calculations were performed using the spin-polarized generalized gradient approximation. A continuum solvation model (VASPsol ${ }^{48,49}$ code) was used to evaluate the solvation energy of the alkali-metal superoxide/peroxide $\left(\mathrm{M}_{x} \mathrm{O}_{2}, \mathrm{M}: \mathrm{Li}, \mathrm{Na}, x=1\right.$ or 2$)$. The following equations were used considering both the (1) molecular and (2) ionized solvated states:

$$
\begin{gathered}
\Delta E_{\text {sol, mol }}=E_{\text {solvated }}\left(\mathrm{M}_{x} \mathrm{O}_{2}\right)-E_{\text {bulk }}\left(\mathrm{M}_{x} \mathrm{O}_{2}\right) \\
\Delta E_{\text {sol, ion }}=x \cdot E_{\text {solvated }}\left(\mathrm{M}^{+}\right)+E_{\text {solvated }}\left(\mathrm{O}_{2}^{x-}\right)-E_{\text {bulk }}\left(\mathrm{M}_{x} \mathrm{O}_{2}\right),
\end{gathered}
$$

where $E_{\text {solvated }}\left(\mathrm{M}_{x} \mathrm{O}_{2}\right)$ and $E_{\text {bulk }}\left(\mathrm{M}_{x} \mathrm{O}_{2}\right)$ are the total energies of the solvated and bulk $\mathrm{M}_{x} \mathrm{O}_{2}$ per formula unit, respectively. The solvated species (ions or molecules) were placed in a $13 \AA \times 13 \AA \times 13 \AA$ cell as an isolated species. We used the planewave basis with an energy cutoff of $550 \mathrm{eV}$ and a Monkhorst-Pack $2 \times 2 \times 2 k$ point mesh. On the basis of previous reports ${ }^{50,51}$ that stated that the solvation entropy term (TS) of polar molecules and ions in the standard state is less than 5\% of the enthalpy term $(H)$, we neglected the entropy effect of the solvation in these calculations.

\section{References}

1. Tarascon, J. M. \& Armand, M. Issues and challenges facing rechargeable lithium batteries. Nature 414, 359-367 (2001)

2. Kang, K., Meng, Y. S., Bréger, J., Grey, C. P. \& Ceder, G. Electrodes with high power and high capacity for rechargeable lithium batteries. Science 311, 977-980 (2006).

3. Abraham, K. M. \& Jiang, Z. A polymer electrolyte-based rechargeable lithium/ oxygen battery. J. Electrochem. Soc. 143, 1-5 (1996).

4. Bruce, P. G., Freunberger, S. A., Hardwick, L. J. \& Tarascon, J.-M. $\mathrm{Li}_{-} \mathrm{O}_{2}$ and Li-S batteries with high energy storage. Nat. Mater. 11, 19-29 (2012).

5. Peng, Z., Freunberger, S. A., Chen, Y. \& Bruce, P. G. A reversible and higherrate $\mathrm{Li}-\mathrm{O}_{2}$ battery. Science 337, 563-566 (2012).

6. Ottakam Thotiyl, M. M. et al. A stable cathode for the aprotic $\mathrm{Li}^{-\mathrm{O}_{2}}$ battery. Nat. Mater. 12, 1050-1056 (2013).

7. Lim, H.-D. et al. Superior rechargeability and efficiency of lithium-oxygen batteries: hierarchical air electrode architecture combined with a soluble catalyst. Angew. Chem. Int. Ed. 126, 4007-4012 (2014).

8. Débart, A., Paterson, A. J., Bao, J. \& Bruce, P. G. $\alpha-\mathrm{MnO}_{2}$ nanowires: a catalyst for the $\mathrm{O}_{2}$ electrode in rechargeable lithium batteries. Angew. Chem. Int. Ed. 47, 4521-4524 (2008).

9. Freunberger, S. A. et al. The lithium-oxygen battery with ether-based electrolytes. Angew. Chem. Int. Ed. 50, 8609-8613 (2011).

10. Yabuuchi, N., Kubota, K., Dahbi, M. \& Komaba, S. Research development on sodium-ion batteries. Chem. Rev. 114, 11636-11682 (2014).

11. Hartmann, P. et al. A rechargeable room-temperature sodium superoxide $\left(\mathrm{NaO}_{2}\right)$ battery. Nat. Mater. 12, 228-232 (2013).

12. Bender, C. L., Hartmann, P., Vračar, M., Adelhelm, P. \& Janek, J. On the thermodynamics, the role of the carbon cathode, and the cycle life of the sodium superoxide $\left(\mathrm{NaO}_{2}\right)$ battery. Adv. Energy Mater. 4, 1301863 (2014).

13. McCloskey, B. D., Garcia, J. M. \& Luntz, A. C. Chemical and electrochemical differences in nonaqueous $\mathrm{Li}_{-} \mathrm{O}_{2}$ and $\mathrm{Na}-\mathrm{O}_{2}$ batteries. J. Phys. Chem. Lett. 5, 1230-1235 (2014)

14. Hartmann, P. et al. Pressure dynamics in metal-oxygen (metal-air) batteries: a case study on sodium superoxide cells. J. Phys. Chem. C 118, 1461-1471 (2014).

15. Liu, W., Sun, Q., Yang, Y., Xie, J.-Y. \& Fu, Z.-W. An enhanced electrochemical performance of a sodium-air battery with graphene nanosheets as air electrode catalysts. Chem. Commun. 49, 1951-1953 (2013).

16. Li, Y. et al. Superior catalytic activity of nitrogen-doped graphene cathodes for high energy capacity sodium-air batteries. Chem. Commun. 49, 11731-11733 (2013).

17. Hu, Y. et al. Porous perovskite calcium-manganese oxide microspheres as an efficient catalyst for rechargeable sodium-oxygen batteries. J. Mater. Chem. A 3, 3320-3324 (2015).

18. Kim, J., Lim, H.-D., Gwon, H. \& Kang, K. Sodium-oxygen batteries with alkyl-carbonate and ether based electrolytes. Phys. Chem. Chem. Phys. 15, 3623-3629 (2013).

19. Yadegari, H. et al. On rechargeability and reaction kinetics of sodium-air batteries. Energy Environ. Sci. 7, 3747-3757 (2014).

20. Zhao, N., Li, C. \& Guo, X. Long-life $\mathrm{Na}-\mathrm{O}_{2}$ batteries with high energy efficiency enabled by electrochemically splitting $\mathrm{NaO}_{2}$ at a low overpotential. Phys. Chem. Chem. Phys. 16, 15646-15652 (2014).

21. Ortiz-Vitoriano, N. et al. Rate-dependent nucleation and growth of $\mathrm{NaO}_{2}$ in $\mathrm{Na}-\mathrm{O}_{2}$ batteries. J. Phys. Chem. Lett. 6, 2636-2643 (2015).

22. Yadegari, H. et al. Three-dimensional nanostructured air electrode for sodiumoxygen batteries: a mechanism study toward the cyclability of the cell. Chem. Mater. 27, 3040-3047 (2015).
23. Aetukuri, N. B. et al. Solvating additives drive solution-mediated electrochemistry and enhance toroid growth in non-aqueous $\mathrm{Li}-\mathrm{O}_{2}$ batteries. Nat. Chem. 7, 50-56 (2015).

24. Xia, C., Black, R., Fernandes, R., Adams, B. \& Nazar, L. F. The critical role of phase-transfer catalysis in aprotic sodium-oxygen batteries. Nat. Chem. 7, 496-501 (2015).

25. Schroeder, M. A. et al. DMSO- $\mathrm{Li}_{2} \mathrm{O}_{2}$ interface in the rechargeable $\mathrm{Li}-\mathrm{O}_{2}$ battery cathode: theoretical and experimental perspectives on stability. ACS Appl. Mater. Interfaces 7, 11402-11411 (2015).

26. Kumar, N., Radin, M. D., Wood, B. C., Ogitsu, T. \& Siegel, D. J. Surface-mediated solvent decomposition in li-air batteries: impact of peroxide and superoxide surface terminations. J. Phys. Chem. C 119, 9050-9060 (2015).

27. Kwabi, D. G. et al. Chemical instability of dimethyl sulfoxide in lithium-air batteries. J. Phys. Chem. Lett. 5, 2850-2856 (2014).

28. Wang, Q., Yang, X.-Q. \& Qu, D. In situ ESR spectro-electrochemical investigation of the superoxide anion radical during the electrochemical $\mathrm{O}_{2}$ reduction reaction in aprotic electrolyte. Carbon 61, 336-341 (2013).

29. Eastland, G. W. \& Symons, M. C. Electron spin resonance studies of superoxide ions produced by radiolysis in alcoholic media. J. Phys. Chem. 81, 1502-1504 (1977).

30. Schechter, D. L. \& Kleinberg, J. Reactions of some metal salts with alkali superoxides in liquid ammonia. J. Am. Chem. Soc. 76, 3297-3300 (1954).

31. Hartmann, P. et al. Discharge and charge reaction paths in sodium-oxygen batteries: does $\mathrm{NaO}_{2}$ form by direct electrochemical growth or by precipitation from solution? J. Phys. Chem. C 119, 22778-22786 (2015).

32. Johnson, L. et al. The role of $\mathrm{LiO}_{2}$ solubility in $\mathrm{O}_{2}$ reduction in aprotic solvents and its consequences for Li- $\mathrm{O}_{2}$ batteries. Nat. Chem. 6, 1091-1099 (2014).

33. Hall, P. \& Selinger, B. Better estimates of exponential decay parameters. J. Phys. Chem. 85, 2941-2946 (1981).

34. Maricle, D. L. \& Hodgson, W. G. Reducion of oxygen to superoxide anion in aprotic solvents. Anal. Chem. 37, 1562-1565 (1965).

35. Okoshi, M., Yamada, Y., Yamada, A. \& Nakai, H. Theoretical analysis on desolvation of lithium, sodium, and magnesium cations to organic electrolyte solvents. J. Electrochem. Soc. 160, A2160-A2165 (2013).

36. Ziegler, M. \& Madura, J. Solvation of metal cations in non-aqueous liquids. J. Solution Chem. 40, 1383-1398 (2011).

37. Lee, B. et al. Theoretical evidence for low charging overpotentials of superoxide discharge products in metal-oxygen batteries. Chem. Mater. 27, 8406-8413 (2015).

38. Petrowsky, M. A. Ion Transport in Liquid Electrolytes ( $\mathrm{PhD}$ thesis, Univ. of Oklahoma, 2008)

39. Kashchiev, D. \& Van Rosmalen, G. Review: nucleation in solutions revisited. Cryst. Res. Technol. 38, 555-574 (2003).

40. Takiyama, H. Supersaturation operation for quality control of crystalline particles in solution crystallization. Adv. Powder Technol. 23, 273-278 (2012).

41. Khetan, A., Pitsch, H. \& Viswanathan, V. Solvent degradation in nonaqueous Li- $\mathrm{O}_{2}$ batteries: oxidative stability versus $\mathrm{H}$-abstraction. J. Phys. Chem. Lett. 5 , 2419-2424 (2014).

42. Khetan, A., Luntz, A. \& Viswanathan, V. Trade-offs in capacity and rechargeability in nonaqueous $\mathrm{Li}-\mathrm{O}_{2}$ batteries: solution-driven growth versus nucleophilic stability. J. Phys. Chem. Lett. 6, 1254-1259 (2015).

43. Sawyer, D. T. \& Valentine, J. S. How super is superoxide? Acc. Chem. Res. 14, 393-400 (1981).

44. Chin, D. H., Chiericato, G., Nanni, E. J. \& Sawyer, D. T. Proton-induced disproportionation of superoxide ion in aprotic media. J. Am. Chem. Soc. 104, 1296-1299 (1982).

45. Hill, G. S. et al. The X-ray structure of a sodium peroxide hydrate, $\mathrm{Na}_{2} \mathrm{O}_{2} \cdot 8 \mathrm{H}_{2} \mathrm{O}$, and its reactions with carbon dioxide: relevance to the brightening of mechanical pulps. Can. J. Chem. 75, 46-51 (1997).

46. Zhai, D. et al. Raman evidence for late stage disproportionation in a $\mathrm{Li}-\mathrm{O}_{2}$ battery. J. Phys. Chem. Lett. 5, 2705-2710 (2014).

47. Zhai, D. et al. Interfacial effects on lithium superoxide disproportionation in Li- $\mathrm{O}_{2}$ batteries. Nano Lett. 15, 1041-1046 (2015).

48. Fishman, M., Zhuang, H. L., Mathew, K., Dirschka, W. \& Hennig, R. G. Accuracy of exchange-correlation functionals and effect of solvation on the surface energy of copper. Phys. Rev. B 87, 245402 (2013).

49. Mathew, K., Sundararaman, R., Letchworth-Weaver, K., Arias, T. A. \& Hennig, R. G. Implicit solvation model for density-functional study of nanocrystal surfaces and reaction pathways. J. Chem. Phys. 140, 084106 (2014).

50. Burgess, J. Metal Ions in Solution (Chichester: Horwood Ellis, 1978).

51. Ben-Amotz, D., Raineri, F. O. \& Stell, G. Solvation thermodynamics: theory and applications. J. Phys. Chem. B 109, 6866-6878 (2005).

\section{Acknowledgements}

This work was supported by the National Research Foundation of Korea (NRF) grand funded by the Korea government (MSIP; No. 2015R1A2A1A10055991) and by the HMC (Hyundai Motor Company). This work was also supported by the BK21PLUS (No. 21A20131912052) and by Project Code (IBS-R006-G1). Y.B. and K.K. also acknowledge to the support of Samsung Advanced Institute of Technology. 


\section{Author contributions}

J.K. and H.P. designed and performed the experiments. B.L. calculated and predicted the solvation energies. W.M.S. examined the morphologies of the discharge products. H.-D.L. and Y.B. contributed to discussions and assisted in integration of the results. H.K. prepared the electrolyte. W.K.K. and K.H.R. supported the electrochemical measurements and characterization under dried conditions. K.K. conceived the original idea, supervised the research, contributed to scientific discussions and writing of manuscript.

\section{Additional information}

Supplementary Information accompanies this paper at http://www.nature.com/ naturecommunications

Competing financial interests: The authors declare no competing financial interests.
Reprints and permission information is available online at http://npg.nature.com/ reprintsandpermissions/

How to cite this article: Kim, J. et al. Dissolution and ionization of sodium superoxide in sodium-oxygen batteries. Nat. Commun. 7:10670 doi: 10.1038/ ncomms10670 (2016)

(c) (i) This work is licensed under a Creative Commons Attribution 4.0 International License. The images or other third party material in this article are included in the article's Creative Commons license, unless indicated otherwise in the credit line; if the material is not included under the Creative Commons license, users will need to obtain permission from the license holder to reproduce the material. To view a copy of this license, visit http:// creativecommons.org/licenses/by/4.0/ 